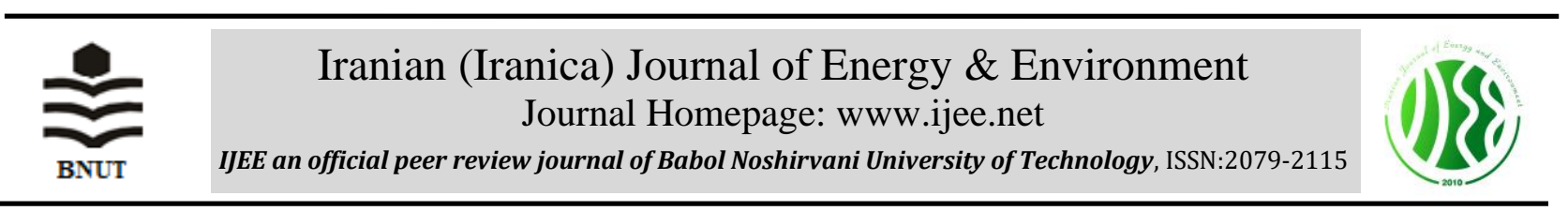

Technical Note

\title{
Energy Saving through Connection of Sunken Garden with Nature and Passive Cooling in Traditional Buildings of Hot and Dry Climate of Iran
}

\author{
F. Mohammad Alinezhad* \\ Department of Architecture, Faculty of Engineering, Shahid Chamran University of Ahvaz, Ahvaz, Iran
}

\section{PAPER IN FO}

\section{Paper history:}

Received 25 November 2019

Accepted in revised form 04 February 2020

\section{Keywords:}

Conservation of Energy

Natural

Passive Cooling

Sunken Garden

\begin{abstract}
A $B$ S S T T R A A C
Sunken garden is one of the elements of traditional Iranian architecture, formed with the attitude of conservation of environment and organizing a meaningful relationship with its surroundings. Many studies have been conducted to identify this element of traditional architecture and its functions, endorsing its valuable and considerable properties in respect for nature, harmony with the aims of sustainable development and energy conservation. One of the most important functions of this elements is providing cooling needs for residents in the hot summer months of desert areas of Iran without the need of fossil fuels consuming. The current article, as a descriptive-analytic study, aimed at a more comprehensive knowledge of passive cooling in sunken garden. To reach this goal, passive cooling and its types and sunken garden were first introduced. Then, their relationship with natural elements and the role of each element in achieving passive cooling in sunken garden were evaluated. The results revealed that sunken garden has been linked with natural elements in a way which cools this underground space of traditional buildings of hot and dry climate of Iran through heat prevention, heat modulation and heat dissipation.
\end{abstract}

\section{INTRODUCTION}

Today, energy conservation is an important international issue, leading architects to environmentally sustainable projects. Traditional Iranian architecture has provided valuable and unique design solutions to protect and preserve nature [1]. Sunken garden is one of these valuable solutions in hot and dry climate. Avoiding the use of fossil fuels for cooling, reducing air dryness and achieving climate comfort is one of the functions of this elements of traditional architecture in achieving environmental sustainability goals. Sunken garden, in fact, is made of a combination of natural and artificial agents. Understanding the relationship among these factors, leading to valuable experiences of the past and create an appropriate attitude for designers in the present age, is considered as the necessity of this research. Therefore, the purpose of the present study was to investigate the cooling performance of sunken garden in traditional desert buildings of Iran and to identify the ways to achieve it by emphasizing its association with natural elements. In this regard, answering the following questions are in high importance:

- What is passive cooling and what are the strategies for achieving it in the buildings?

- What is the relationship between sunken garden and natural elements in traditional buildings of hot and dry climates of Iran?

- How does the connection of sunken garden with natural elements provide passive cooling in traditional buildings of hot and dry climates of Iran?

For achieving the goals of the present article, a literature review was carried out in a descriptive-analytic method. In this regard, passive cooling in the building was described, sunken garden and its functions were presented and, finally, the relationship between sunken garden and nature in the creation of passive cooling was considered.

\section{PASSIVE COOLING}

Passive cooling, is used to provide thermal comfort during hot season of the year through numerous heat reducers [2] Strategies for achieving passive cooling in the buildings can be categorized as shown in Figure 1 [2-5].

\footnotetext{
*Corresponding Author Email: f.mohammadalinezhad@scu.ac.ir

(F. Mohammad Alinezhad)
} 


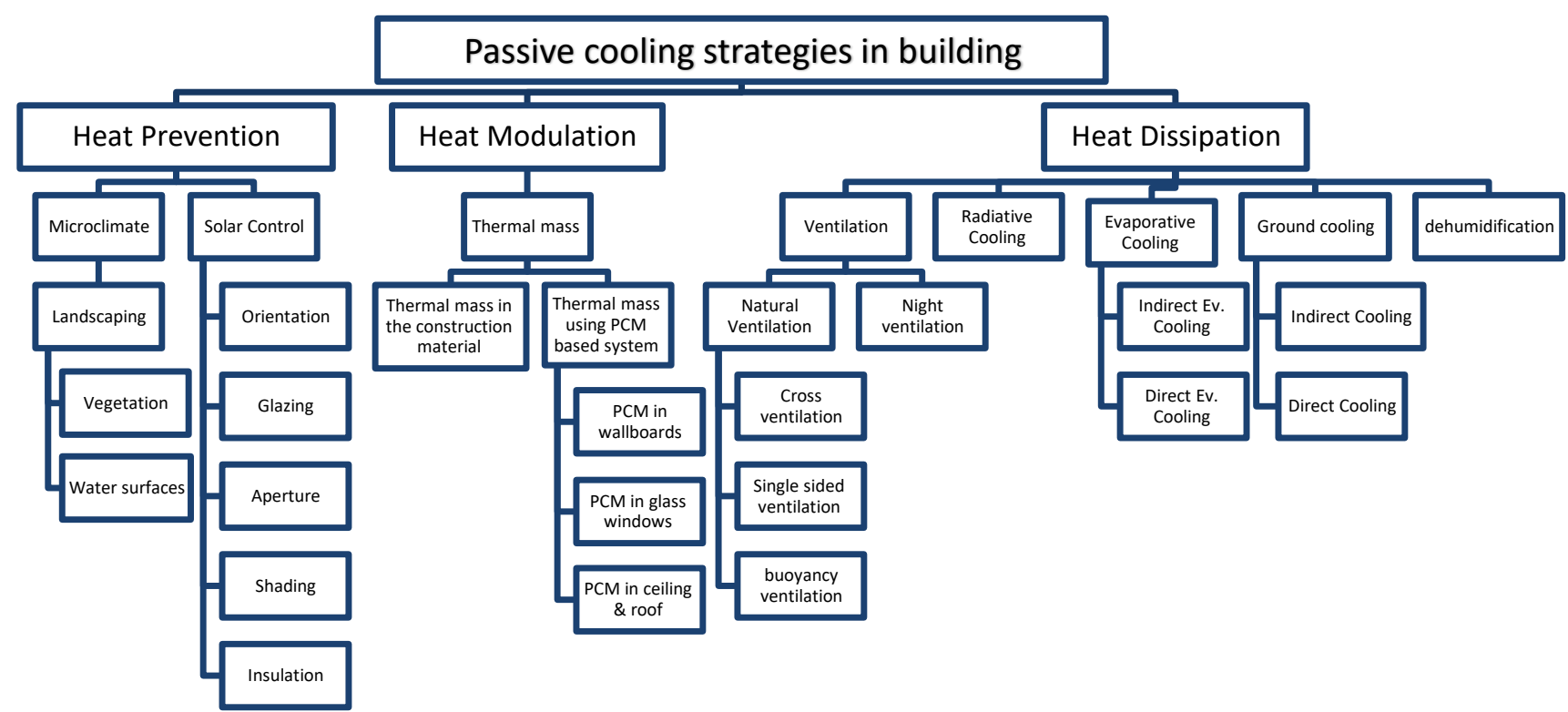

Figure 1. Strategies for passive cooling creation in buildings [2-5]

\section{Heat prevention}

This strategy, which is more about controlling radiation and avoiding the entrance of heat from the outside [5], includes two methods of microclimate creation and control of radiation [4]. In very hot climate defensive solutions are used to provide comfort and prevent the absorption of radiation and the transfer of heat [6]. Orientation, glazing, aperture, shading and insulation are methods used for the control of radiation [3-5]. An average of atmospheric parameters during a long period of time over a large region is considered as climate. Microclimate is a small scale pattern of climate which is resulted from the effect of soil properties (texture and structure), the form of ground and topography. Air temperature, relative humidity, precipitation and wind speed are among the most important parameters characterizing climate. Creating a suitable microclimate is possible through appropriate landscaping, using water level and vegetation [3].

\section{Heat modulation}

This strategy, referring to controlling indoor heat flux through heat storage techniques [5], is suitable for places with temperature fluctuations between $20-35^{\circ} \mathrm{C}$ [7]. This strategy works in buildings in two ways of thermal mass in the construction material and thermal mass using phase change material (PCM). Achieving thermal mass of a building can be occurred in two ways: using a material for energy intensive phase change in the building and using the material of bulky construction. Because of more efficient heat exchange and easier execution, PCMs are commonly studied for integrated in wallboards, roof and ceilings [3].

\section{Heat dissipation}

In this strategy, heat is eliminated through releasing into a natural reservoir such as water, air and earth [5]. Heat is discharged from the building to the natural heat reducers and heat radiated from the sun is naturally adjusted [6]. This strategy includes ventilation cooling, ground mass cooling, dehumidification cooling, evaporative cooling and radiative cooling $[2,5]$ which are described below.

Ventilation Cooling by ventilation includes natural ventilation and night ventilation [8]. Natural ventilation, as the main technique of cooling, is the natural flow of air induced by temperature and pressure differences.

In the night ventilation thermal materials are used to absorb daytime heat and to discharge this stored heat through ventilation and cooling at night [7]. It is directly related to thermal mass characteristics used in the walls of the buildings and the surface of the openings $[7,9]$.

\section{Evaporative cooling}

At humid surfaces, the heat exchange of air with the latent heat of water droplet is defined as evaporative cooling [10]. In other words, the dry and warm air passing through the water surfaces causes the air to evaporate the water droplets resulting in cool and humid air [11]. In this method, building air is cooled in both direct and indirect approaches [2].

Radiative cooling Radiative cooling is a form of heat transfer from a warmer surface to the surrounding cool surface. Nocturnal radiation in the building from walls and dense building materials results in radiative cooling [2].

Ground cooling As the depth of the earth increases, the annual fluctuations in soil temperature decrease and allow the use of the constant ground temperature to cool the building [2]. This cooling type is occurred in two ways of direct and indirect. In direct type of cooling, the walls of the building fall almost or completely underground and indirectly cooled by heat exchangers, such as pipes or tunnels, buried in the ground [6].

Dehumidification

Dehumidification is defined as extracting of water vapor from the air when the relative humidity of the air is between $70-80$ percent $[2,10]$. 


\section{SUNKEN GARDEN}

Sunken garden is an appropriate response to desert drought and heat. In fact, sunken garden is a part of central courtyard which appears in the courtyard. Around sunken garden, there are often porches and several rooms (Figures 2 and 3). Sunken garden will make the construction more resistant to earthquake [12].

Evaluation of sunken garden function in environmental point of view revealed that sunken garden was a suitable place for avoiding hot summers. The sunken garden architecture in relation to surrounding environment has been formed to conserve energy and reduce the use of artificial resources.

\section{SUNKEN GARDEN, NATURE AND PASSIVE COOLING}

The architecture of desert region of Iran was design in accordance with the reduction of using fossil fuel. Sunken garden cleverly works against heat and wind with creating a microclimate and supply a cool space and comfort for its residents through positive relation to the environment. The relationship between sunken garden and environmental elements and its role in passive cooling and moderate adverse environmental conditions will be more discussed.

\section{Sun}

The central courtyard exhibits appropriate management of the natural energy of sun [13]. The central courtyard of the Iranian desert houses makes two parts for summer and winter using [14] which coincided with sun movement around central courtyard. The southern parts was located in shade and the northern one exploited the sun radiation [13] which also occurs for central courtyards having sunken garden. According to Figure 4, since sunken garden is located in the depth of the earth, its shading is more than that of courtyards having no sunken garden.

\section{Water}

In the past, water resources and facilities had a decisive role in the formation of settlements. One of the main factors affecting the emergence of the sunken gardens was access to running water in the aqueduct placed in a short distance from the subhouses [15]. Water in sunken gardens offset the dryness of the air. Air flow contact with water assist to increase the relative humidity of the air [16]. Furthermore, the presence of water inside the building results in space cooling. Some examples of the presence of water in sunken garden is presented in Figure 5.
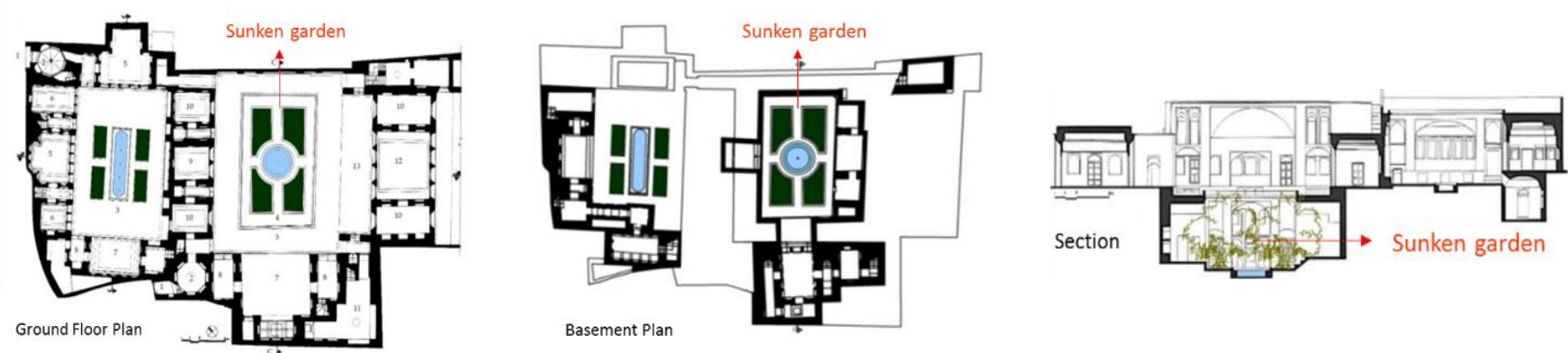

Figure 2. A house in dry and tropical region with sunken garden [17]
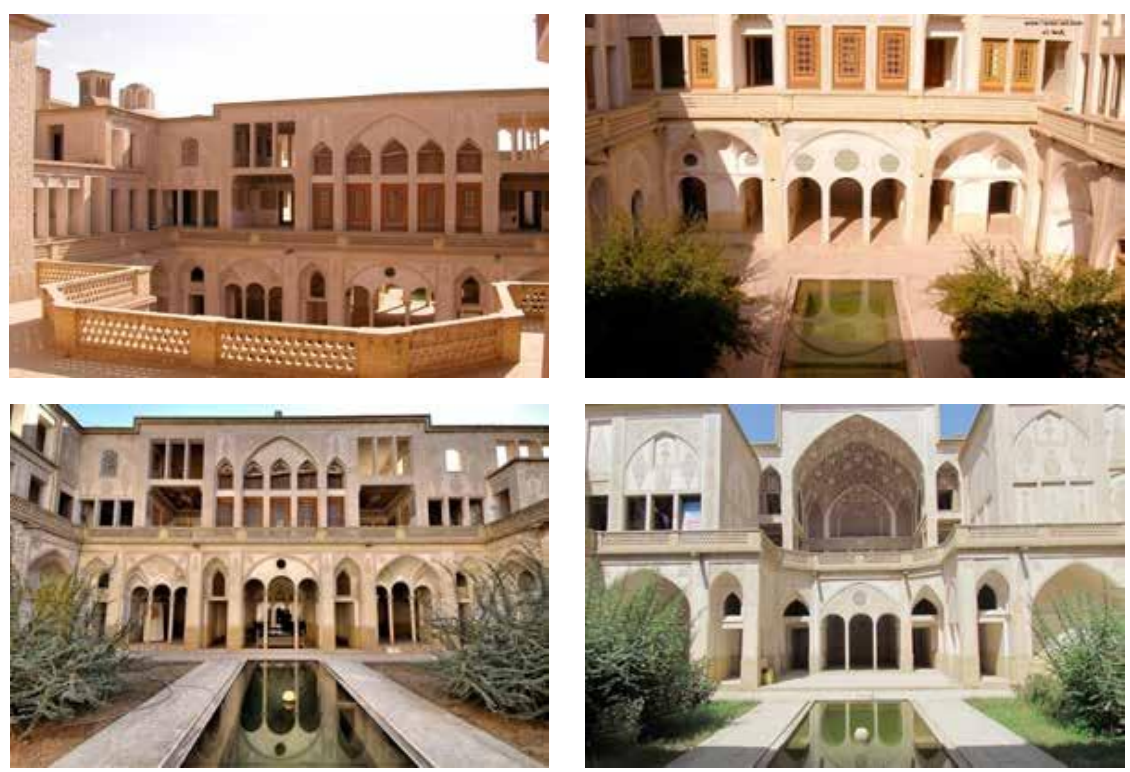

Figure 3. Sunken garden in Abbasian house in Kashan, Iran [18] 

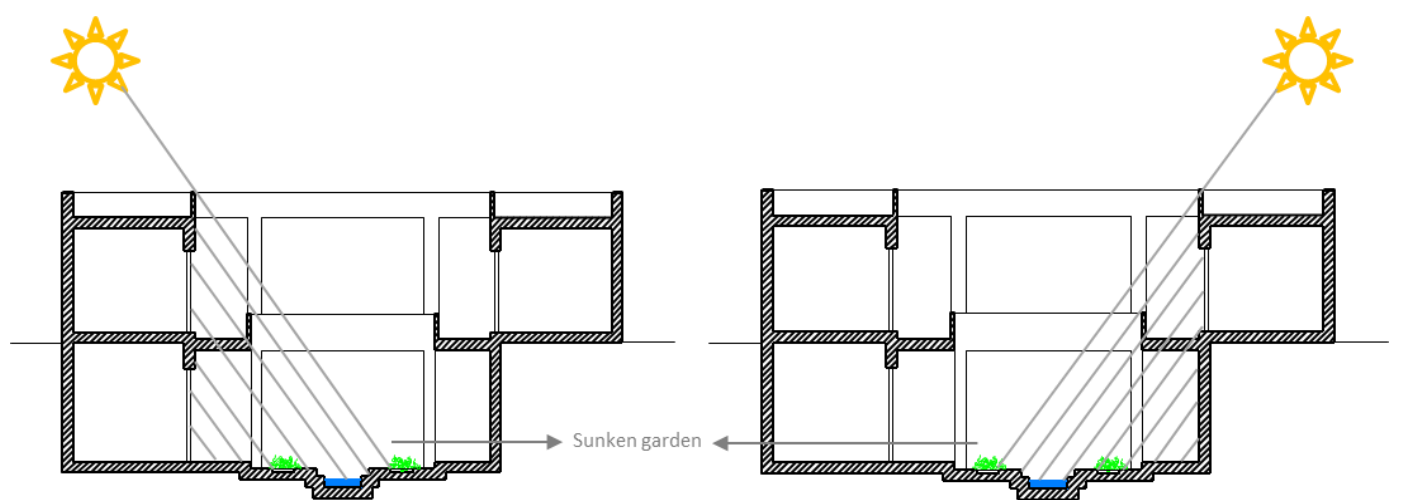

Figure 4. Schematic view of the presence of shade at different times of day in the sunken garden and the surrounding spaces and its more surface compared with central courtyard
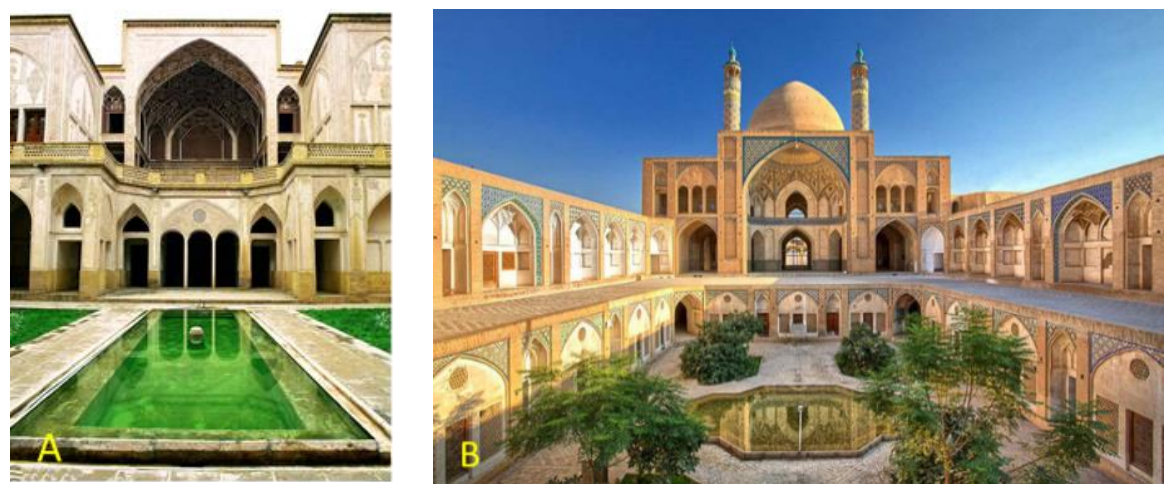

Figure 5. Water pond in sunken garden. A: Abbasian house in Kashan, $\operatorname{Iran}^{1}$. B: Agha-Bozorg Mosque and school in Kashan, Iran ${ }^{2}$

Regarding the role of water in sunken garden and different types of passive cooling, the role of water in heat prevention through providing micro climate, heat dissipation through increasing the relative humidity of the air and evaporative cooling can be more considered.

\section{Plants}

Microclimate and energy use of buildings are modified by vegetation through reduction of air and surface temperatures that may increase the relative humidity of the air [3].

In sunken garden, trees reduce heat (through creating shade) and increase environmental relative humidity. This is crucial for cooling the spaces around the sunken garden, emphasizing the important role of plants for heat prevention by making a microclimate. Some examples of plant presence in sunken garden are presented in Figure 6.

\section{Wind}

In central courtyard, the shadow created in the southern parts has a lower temperature than that of northern parts, receiving solar radiation. Due to pressure difference, warm air in northern part causes air circulation throughout the yard [16]. Such air conditioning is also seen in sunken garden. Warm winds pass above the house during the day and do not penetrate into the sunken garden (Figure 7). In the evening, the air of sunken garden which was warmed during the day by absorbing the solar radiation rises and cool air replaces it. (Figure 8) Cool air is stored in the wall of sunken garden and, then, moves to surrounding space. It remains cold in the morning until the sun shines directly on the yard. As a final remark it can be concluded that in sunken garden, heat dissipation strategy, provides cooling through natural and night ventilation.

\section{Land and soil}

Because of sunken garden, a floor falls into the heart of the ground, resulting in lower temperature in summer and minimizing waste and fluctuation of energy [16]. This attribute in sunken garden causes a type of passive cooling named ground cooling which is one the passive cooling strategies for heat dissipation.

The soil, mud and sands are the main building materials used in hot and dry regions. These building materials were climate-friendly. Their recyclability and longevity minimized environmental degradation and non-construction waste [13] (Figure 9). Adobe walls have a high thermal capacity and, thus, absorb solar energy during summer days. However, because of low thermal transferring coefficient, heat transfer is effectively delayed, where for thick adobe walls (with approximately $6 \mathrm{~cm}$ thickness) heat transfer lasts all day

\footnotetext{
1 https://www.iranroute.com/sights/294/abbasian-house

2 https://www.iranroute.com/sights/299/agha-bozorg-mosque
} 


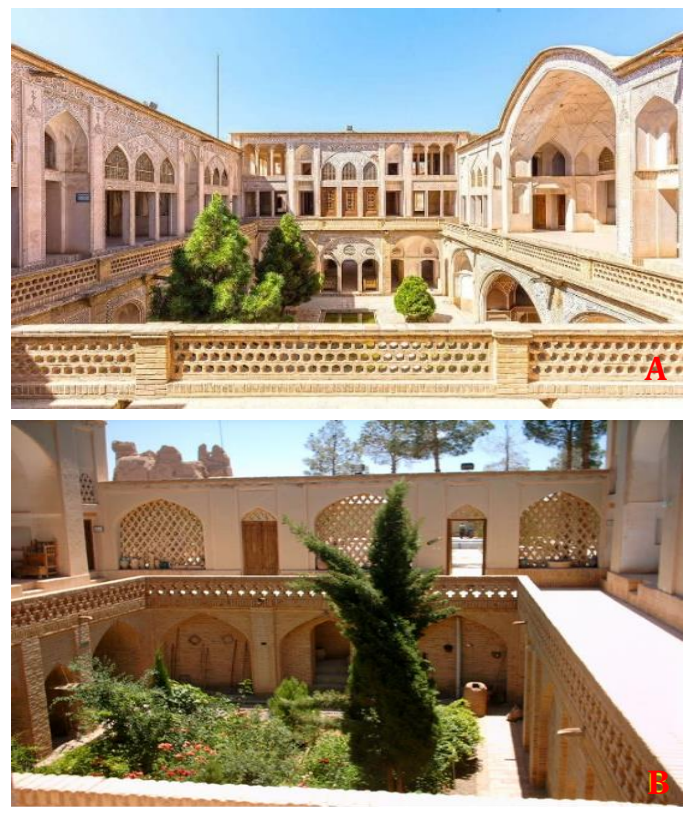

Figure 6. Plants in sunken garden. A: Abbasian house in Kashan, Iran $^{1}$. B: Pirnia house in Naeen, Iran ${ }^{2}$

time and reaches to inner layer at night. Due to difference in day and night temperatures, the walls lose their temperature at night and indoor air ventilation will create a moderate temperature inside the space at morning. Color and fine texture of adobe results in limited radiation absorption and high reflectance scattering [16]. The mentioned properties of adobe indicate the effect of this natural element in passive cooling through three strategies of heat prevention, heat dissipation and heat modulation. The role of adobe in buildings cooling through heat prevention is carried out though high reflectance scattering. Adobe, in accordance with heat modulation strategy, prevents heat from entering the area around the sunken garden due to high thermal capacity and heat storage. Other factors that regulate the temperature of sunken garden and its surrounding areas are nocturnal radiation due to the temperature difference between adobe and brick (used in the wall and floor of sunken garden) and the surrounding air at night. This indicates the radiative cooling, as a method of heat dissipation strategy, in the building.

The types of cooling through sunken garden and its connection with natural elements in hot and dry climatic conditions of Iran are as summarized in Table 1.

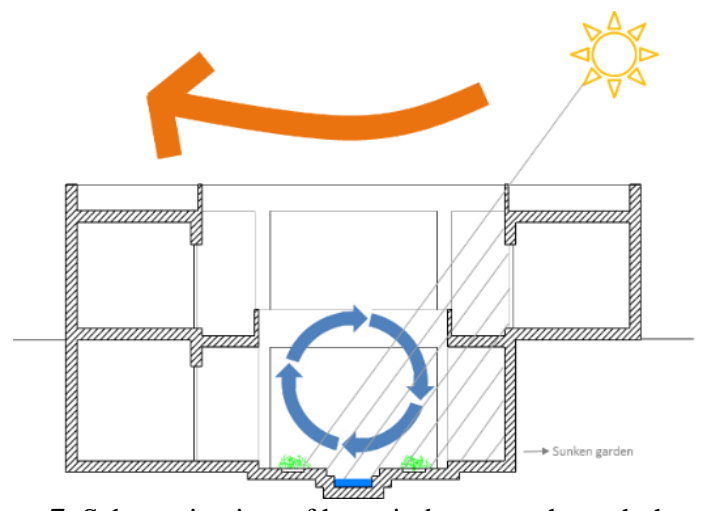

Figure 7. Schematic view of hot winds passes through the top of the sunken garden and the air circulates inside it during day
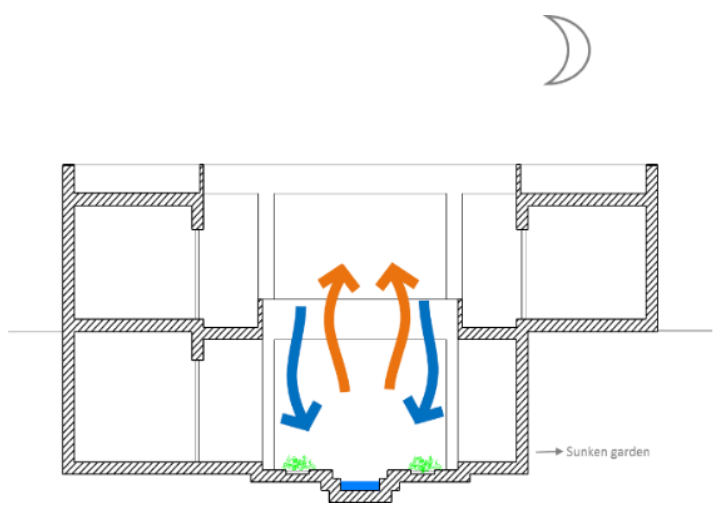

Figure 8. Schematic view of night ventilation in sunken garden
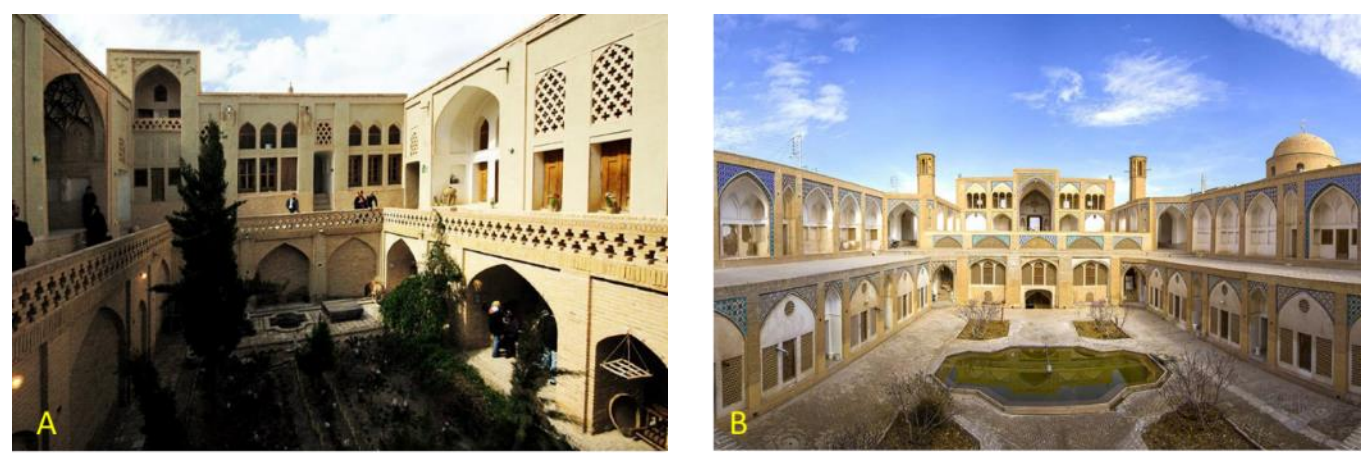

Figure 9. Use of materials with high thermal capacity on the wall and floor of the sunken garden. A: Pirnia house in Naeen, Iran ${ }^{3}$. B: Mosque and school of Agha-Bozorg in Kashan, Iran ${ }^{4}$

\footnotetext{
${ }^{1}$ https://www.iranroute.com/sights/294/abbasian-house

${ }^{2} \mathrm{http} / / /$ naeeni.com/home-pirnia-nain
}

$3 \mathrm{http}: / /$ naeeni.com/home-pirnia-nain
${ }^{4} \mathrm{https} / / / \mathrm{www}$.iranroute.com/sights/299/agha-bozorg-mosque 
TABLE 1. Passive cooling in sunken garden and its surrounding spaces in relation to nature

\begin{tabular}{|c|c|c|}
\hline Passive cooling strategies & & Energy saving in relation of sunken garden and nature \\
\hline \multirow[t]{4}{*}{ Heat prevention } & microclimate & Moderation of temperature and increasing relative humidity with the presence of water and plants \\
\hline & Control of radiation & - shading by dipping into the depth of the earth \\
\hline & & - shading by trees \\
\hline & & - high reflectance scattering of adobe in the surrounding walls of sunken garden \\
\hline \multirow[t]{2}{*}{ Thermal fluctuation } & Thermal mass & $\begin{array}{l}\text { - moderating ambient temperature and prevent heat from entering the sunken garden are during day } \\
\text { due to the high thermal capacity of the adobe walls. }\end{array}$ \\
\hline & & $\begin{array}{l}\text { - moderating ambient temperature due to high thermal capacity of brick existed at the bottom of the } \\
\text { sunken garden. }\end{array}$ \\
\hline \multirow[t]{4}{*}{ Heat dissipation } & Ventilation cooling & - moderating temperature by air flow through natural ventilation and night ventilation. \\
\hline & Evaporative cooling & $\begin{array}{l}\text {-increasing humidity and modification of environmental temperature due to water evaporation } \\
\text { accompany with wind passing on water }\end{array}$ \\
\hline & Radiative cooling & $\begin{array}{l}\text {-decreasing the temperature of sunken garden and its surrounding spaces by nocturnal radiation } \\
\text { from the brick existed at the bottom and adobe walls to the cool night air }\end{array}$ \\
\hline & Ground cooling & $\begin{array}{l}\text {-cooling through the effect of mass by dipping into the ground and using the balanced temperature } \\
\text { of the depth of the earth }\end{array}$ \\
\hline
\end{tabular}

\section{CONCLUSION}

In the hot and dry climates of Iran, the sunken garden has cleverly interacted with its surrounding nature and plays an important role in mitigating the harsh climatic conditions. Passive cooling, through making a sunken garden, will conserve energy and meet the environmental goals of sustainable development. Studies revealed that the relation between sunken garden and its surrounding nature is created in such a way that all three passive cooling strategies occur.

\section{REFERENCES}

1. Vaezizadeh, F., Rashidisharifabad, S. and Afhami, R., 2016. Investigating the Cooling Effect of Living Walls in the Sunken Courtyards of Traditional Houses in Yazd. European Journal of Sustainable Development, 5(2), pp.27-27.

2. Vakilinezhad, R., Mehdizadeh Seradj, F. and MofidiShemirani, S.M., 2013. Principles of Passive Cooling Systems in Vernacular Architectural Elements of Iran. Journal of Iranian Association of Architecture \& Urbanism, 4(5), pp.147-159.

3. Geetha, N.B. and Velraj, R., 2012. Passive cooling methods for energy efficient buildings with and without thermal energy storage-A review. Energy Education Science and Technology Part A: Energy Science and Research, 29(2), pp.913-946.

4. Panchabikesan, K., Vellaisamy, K. and Ramalingam, V., 2017. Passive cooling potential in buildings under various climatic conditions in India. Renewable and Sustainable Energy Reviews, 78, pp.1236-1252.

5. Prieto, A., Knaack, U., Klein, T. and Auer, T., 2017. 25 Years of cooling research in office buildings: Review for the integration of cooling strategies into the building façade (1990-2014). Renewable and Sustainable Energy Reviews, 71, pp.89-102.

6. Moore, F. and McGraw-Hill architecture and urban planninig series, 1993. Environmental control systems: Heating, cooling, lighting. New York: McGraw-Hill.

7. Shafiei-Ardestani, L. and Mofidi-Shemirani, S.M., 2009. Geographical factors and static cooling in residential complex. Scientific-Research Quarterly of Geographical Data (SEPEHR), 18(71), PP.38-46. [In Persian]
8. Ahadi A.A. and Alirezaei Vernosfaderani, B., 2015. Evaluating appropriate roof shape and efficiency of wind tower and wind scoop for natural ventilation in residential buildings of Chabahar. Journal of Housing and Rural Environment, 33(148), pp.33-44.

9. Solgi, E., Kari, B.M., Fayaz, R. and Taheri, H., 2017. The impact of phase change materials assisted night purge ventilation on the indoor thermal conditions of office buildings in hot-arid climates. Energy and Buildings, 150, pp.488-497.

10. Mohammad Alinezhad, F., 2019. Passive Cooling in Shavadoon of Traditional Buildings of Dezful City: Cooling Through Renewable Energy Sources. Iranian (Iranica) Journal of Energy \& Environment, 10(2), pp.115-120"

11. Pourahmadi, M., 2013. The Examination of Sustainable Patterns in the Architecture of Mehriz Traditional Houses. Journal of Architecture in Hot and Dry Climate, 3(3), pp.55-64. [In Persian]

12. Nasiri, S., 2018. A Study on the Role of Sunken Courtyard in Sustainable Architecture of Iranian Desert Cities (Case Study: Olumi House in Yazd). In: Kerpic'18 - Back to Earthen Architecture: Industrialized, Injected, Rammed, Stabilized $6^{\text {th }}$ International Conference Hasan Kalyoncu University, Turkey, pp.229-238.

13. Ahmadi, Z., 2012. Recognize the missing role of central courtyard to achieve sustainable architecture. Journal of Architecture in Hot and Dry Climate. 2(2), pp. 25-40. [In Persian]

14. Zarei, E.M., Ashkezari, S.F.M. and Yari, M., 2017. The investigation of the function of the central courtyard in moderating the harsh environmental conditions of a hot and dry climate (Case study: City of Yazd, Iran). Spatium, 38, pp.1-9.

15. Soltanzadeh, H., 2011. The role of geography in forming different types of courtyards in the traditional houses of Iran. Geographical Research Quarterly, 42, pp.69-86.

16. Ahmadi, F., 2006. Central courtyard city-house: sustainable city-house, Spiritual city-house. Soffeh Journal. 15(41), pp. 90-113.

17. Tafti, F.A., Rezaeian, M. and Razavi, S.E., 2018. Sunken courtyards as educational environments: Occupant's perception and environmental satisfaction. Tunnelling and Underground Space Technology, 78, pp.124-134.

18. Beigli, F. and Lenci, R., 2016. Underground and semi underground passive cooling strategies in hot climate of Iran. Journal of Environmental Science. 5(3), pp.1-12. 


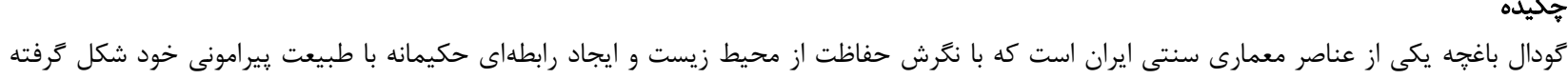

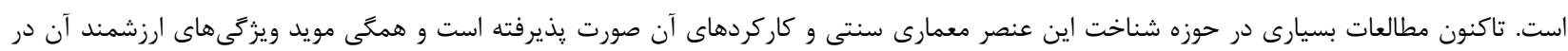

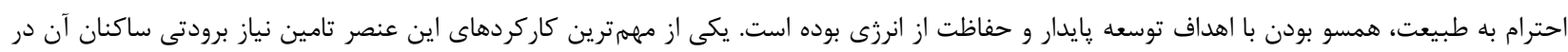

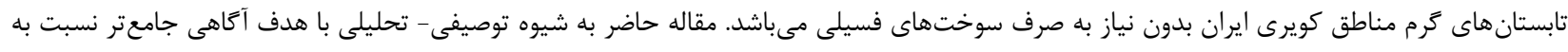

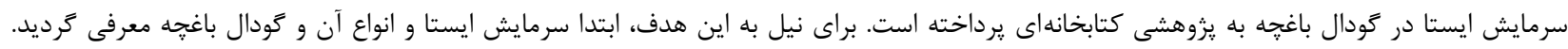

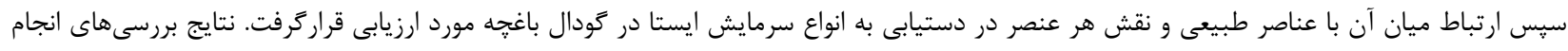

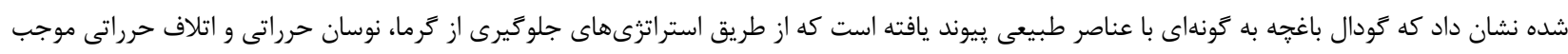

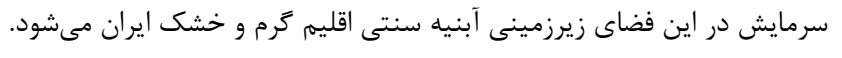

